\title{
The ecology of COVID-19 and related environmental and sustainability issues
}

\author{
Qinfeng Guo $(\mathbb{D}$, Danny C. Lee
}

Received: 31 January 2021/Revised: 15 May 2021/Accepted: 5 July 2021/Published online: 19 July 2021

\begin{abstract}
Around the globe, human behavior and ecosystem health have been extensively and sometimes severely affected by the unprecedented COVID-19 pandemic. Most efforts to study these complex and heterogenous effects to date have focused on public health and economics. Some studies have evaluated the pandemic's influences on the environment, but often on a single aspect such as air or water pollution. The related research opportunities are relatively rare, and the approaches are unique in multiple aspects and mostly retrospective. Here, we focus on the diverse research opportunities in disease ecology and ecosystem sustainability related to the (intermittent) lockdowns that drastically reduced human activities. We discuss several key knowledge gaps and questions to address amid the ongoing pandemic. In principle, the common knowledge accumulated from invasion biology could also be effectively applied to COVID-19, and the findings could offer much-needed information for future pandemic prevention and management.
\end{abstract}

Keywords Assessment - Disease ecology - Epidemics . Environment · Knowledge gaps $\cdot$ Retrospective approach

COVID-19 (coronavirus disease), a pandemic caused by the SARS-CoV-2 virus, has devastated lives and livelihoods worldwide, causing widespread deaths and massive economic impacts (Di Marco et al. 2020; Diffenbaugh et al. 2020; McNeely 2021). Projections of economic losses are as high as US\$ 24 trillion in added global debt during the first year of the pandemic (up to 17 February 2021; https://www.iif.com/publications/globaldebtmonitor). The global pandemic has touched all nations, revealing latent societal problems in health care systems, social equity, and environmental management among others (Table 1, Fig. 1) (Rume and Islam 2020). For scientists, the pandemic and associated response measures offer unique opportunities to re-evaluate socioeconomic networks and their relationships to longterm ecosystem sustainability (Cawthorn et al. 2021; Wu 2021). While traditional studies have commonly investigated how human activities affect the environment, now it becomes urgent to conduct rarely available retrospective tests on how environmental conditions respond to radical and abrupt changes in human activities. For example, one indirect consequence of COVID-19 is the quick return of cleaner air and water in urban areas due to reduced automobile traffic, with concomitant reduced carbon emissions and fewer accidents (Hallema et al. 2020; Le Quéré et al. 2020; Le et al. 2020; Liu et al. 2020; Tobías et al. 2020; Zambrano-Monserrate et al. 2020). Another potential focus of related studies is the impact of the return to "normal" human activities on the future environment as the pandemic winds down in different parts of the world.

Considerable efforts have been made to develop effective vaccines based on molecular-level research and to understand the vectors and pathways of COVID-19 infections in order to reduce/stop its spread. By comparison, understanding of the ecological impacts of COVID-19 is rather poor, which hinders our ability to address related environmental, social, and economic challenges. The time has now arrived to evaluate what has been learned thus far, even as additional studies document real-time changes in social-environmental factors and their consequences. Whereas most published COVID-19-related reports target a specific aspect of environment, economy, or society, a more comprehensive view or synthesis is still lacking. This Perspective is an early step toward this purpose. 
Table 1 Examples of short- vs. expected long-term effects of COVID-19 lockdowns on the environment, economics, and society (Fig. 1). Since the pandemic is still ongoing, it is difficult to estimate or project the long-term and overall effects. Note that many of the cascading or indirect effects from COVID-19 are not included even as we recognize that many environmental variables are likely to interact (Cooke et al. 2021). For example, the reduced air/water pollution (which is likely to be transient) is related to reduced human activities (e.g., traffic, trade) and subsequently reduced energy demand and consumption. In addition, the lockdowns may have reduced international species introductions, but at the same time it also delays the control and management of existing non-native invasive species

\begin{tabular}{|c|c|c|c|c|}
\hline & $\begin{array}{l}\text { Short- } \\
\text { term }\end{array}$ & $\begin{array}{l}\text { Long- } \\
\text { term }^{\text {a }}\end{array}$ & Lessons and consequence & References $^{\mathrm{b}}$ \\
\hline \multicolumn{5}{|l|}{ Environment } \\
\hline $\begin{array}{l}\mathrm{CO}_{2} \text { emission } \\
\text { reduction/air quality }\end{array}$ & + & $?$ & Lessons for future sustainability & $\begin{array}{l}\text { Le et al. (2020), Liu et al. (2020), Le Quéré et al. (2020), Tobías et al. (2020), } \\
\text { Venter et al. (2020) [but see Sicard et al (2020) and Huang et al. (2021)] }\end{array}$ \\
\hline Water quality & + & $?$ & Lessons for future sustainability & Hallema et al. (2020), Cawthorn et al. (2021) \\
\hline Lowered noise levels & + & $?$ & Lessons for future sustainability & Derryberry et al. (2020) \\
\hline Wildlife habitat & + &,$+ ?$ & $\begin{array}{l}\text { Less future contacts with } \\
\text { humans }\end{array}$ & Rutz et al. (2020), Rume and Islam (2020) \\
\hline Human/wildlife health & - &,$- ?$ & $\begin{array}{l}\text { Human-wildlife reciprocal } \\
\text { infections }\end{array}$ & Tan and Robillard (2021), McNeely (2021) \\
\hline Biodiversity &,$+--^{\mathrm{c}}$ &,$+-{ }^{\mathrm{c}}$ & Reduced conservation practice & Corlett et al. (2020), Lindsey et al. (2020), Cooke et al. (2021) \\
\hline Biotic invasions &,$+-^{\mathrm{c}}$ &,$+-^{\mathrm{c}}$ & $\begin{array}{l}\text { Reduced introductions but also } \\
\text { delayed/distracted } \\
\text { management }\end{array}$ & Cooke et al. (2021) \\
\hline Waste management & - & - & $\begin{array}{l}\text { More medical wastes (e.g., } \\
\text { disinfectants), reduced } \\
\text { recycling }\end{array}$ & Adyel (2020), Zambrano-Monserrate et al. (2020) \\
\hline $\begin{array}{l}\text { Other environment } \\
\text { issues }\end{array}$ & - & - & Distractions/delays, disinfectants & Adyel (2020), Zambrano-Monserrate et al. (2020) \\
\hline \multicolumn{5}{|l|}{ Economy } \\
\hline Global economy & $\begin{array}{l}-5 \% \text { (to } \\
\text { date) }\end{array}$ & - & Needs a long time to recover & McNeely (2021), Wu (2021) \\
\hline Growth/income & - & - & ?? & McNeely (2021), Wu (2021) \\
\hline $\begin{array}{l}\text { Employment, airlines, } \\
\text { farming, fisheries, } \\
\text { sports }\end{array}$ & - & - & Higher poverty & McNeely (2021), Wu (2021) \\
\hline Global trade & $\begin{array}{l}-32 \% \\
(2020)\end{array}$ &,$- ?$ & May recover to some extent & McNeely 2021; Wu 2021 \\
\hline Global debt & $\begin{array}{l}+\$ 24 \\
\text { trillion }\end{array}$ & More & $?$ & www.iif.com (17 February, 2021) \\
\hline Food security/safety & - & - & Innovations in related sectors & McNeely (2021), Rume and Islam (2020) \\
\hline Tourism (all levels) & - &,$- ?$ & May recover to some extent soon & Bakar and Rosbi (2020), Karabulut et al. (2020) \\
\hline \multicolumn{5}{|l|}{ Society } \\
\hline Social activity & - & - & Pandemic depression & McNeely (2021), Wu (2021) \\
\hline $\begin{array}{l}\text { Traffic (fewer } \\
\text { accidents) }\end{array}$ & + & + & Hybrid workforce & Wu (2021) \\
\hline Education & - &,$- ?$ & Hybrid learning & McNeely (2021) \\
\hline Health care & - &,-+ & $\begin{array}{l}\text { Preparedness and reform are } \\
\text { needed; vaccines for other } \\
\text { viruses }\end{array}$ & WHO.int/news-room/q-a-detail/one-health \\
\hline Globalization & - & $?$ & Less travel $/$ trade,$\ldots$ & Farzanegan et al. (2021) \\
\hline Lifestyle & - & $?$ & $\begin{array}{l}\text { Less freedom, hybrid workforce, } \\
\quad \ldots\end{array}$ & Cawthorn et al. (2021) \\
\hline Racial/gender equality & - & $?$ & Lessons for the future & Cawthorn et al. (2021), Rume and Islam (2020) \\
\hline
\end{tabular}

${ }^{a}$ The long-term effects would be region- or nation-specific, depending on what happens next and whether we take the lessons from the ongoing COVID-19 pandemic seriously (i.e., whether timely and sufficient mitigation efforts can be made in the future)

${ }^{\mathrm{b}}$ For short-term effects only

${ }^{\mathrm{c}}$ Some of the effects from COVID-19 could be both positive in some aspects (e.g., less human disturbance due to COVID-19 would promote biodiversity) and negative in others (economic loss and fewer human resources would reduce conservation efforts, thus promote diversity loss). COVID-19 reduces the globalization processes in many aspects such as international trade/travel, but increases global collaboration in related medical research and vaccine development

(C) This is a U.S. government work and not under copyright protection in the U.S.; foreign copyright protection may apply 2021 www.kva.se/en 


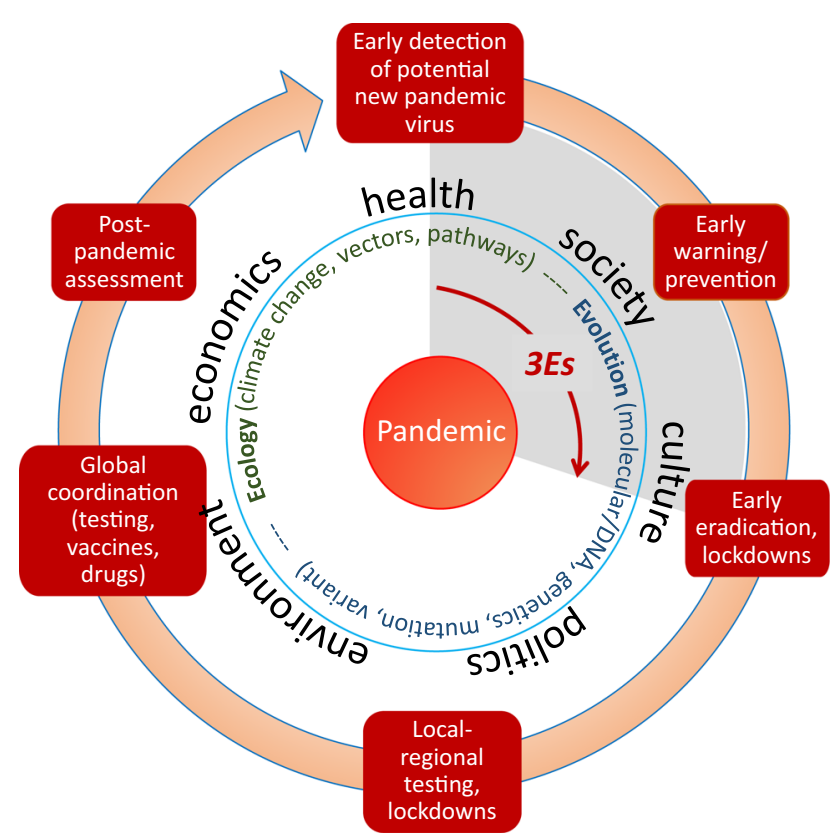

Fig. 1 Stages of pandemic progression and response, which may vary depending on the specific virus, from $3 E$ s (i.e., early detection, early warning, early eradication) to post-pandemic assessment. In practice, if once such virus or emerging infectious disease (EID) is identified, some level of global response (e.g., through WHO's One Health) and scientific inquiry may be needed throughout the entire cycle. For example, early engagement of ecologists during the initial lockdowns improves understanding of how the sudden decline in human activities may affect the environment (Table 1). Similarly, molecular biologists and medical experts should constantly monitor how the virus may mutate and/or develop new variants (e.g., the Delta variant)

\section{RARE AND UNIQUE OPPORTUNITIES FOR RESEARCH}

Scientists worldwide have stepped forward to examine the cascading consequences of extremely rare events associated with COVID-19 (Bivins et al. 2020). The unique circumstances and rapid development of the pandemic require- most studies to be retrospective (e.g., applying lessons on what worked in the past, what did not, and why). Many researchers are using novel techniques or taking advantage of widely accessible remote sensing data that have been adapted and repurposed from their original intended uses. For example, Bivins et al. (2020) developed Wastewater-Based Epidemiology (WBE), a new approach of "environmental surveillance" to trace and test the infection prevalence of SARS-CoV-2 RNA in wastewater during early outbreaks/spread. Another frequently cited example is from the satellite data showing significant reductions of $\mathrm{NO}_{2}$ (nitrogen dioxide) over major cities in China, Europe, the USA, and India following lockdowns enforced to slow the spread of SARS-CoV-2 (Table 1) (but see Le et al. 2020; Sicard et al. 2020; Venter et al. 2020; Huang et al. 2021). Rutz et al. (2020) outlined how to use
COVID-19 pandemic lockdowns to quantify the human effects on wildlife (various wildlife species seemed to have prospered during lockdowns). Buckley (2020) and Corlett et al. (2020) have pointed out potential effects of COVID19 on biodiversity conservation. Derryberry et al. (2020) observed that reduced noise pollution due to the lockdown immediately yielded benefits to wildlife (specifically birds). Reduced artificial light during the lockdowns (Jechow and Hölker 2020) may show similar benefits.

Opportunities abound for studying many other ecological and environmental aspects to address co-occurring physical (i.e., ecological) and social issues (Table 1). Other comprehensive actions include testing how degraded habitat and climate conditions could recover when massive human activities suddenly stop (Phillips et al. 2020; Zambrano-Monserrate et al. 2020). Monitoring could also examine not only the rates at which air or water becomes cleaner and more polluted again, but also at what human activity or disturbance level (Liu et al. 2020). Such observations might provide guidance as to the level of effort required to substantively improve air and water quality, even if not to pre-industrial levels. Before COVID19 , we might not have expected that air and water quality could improve over large scales so rapidly, so these observed short-term changes raise new hope for the possibility of future, longer-term progress. The clear evidence of "quick recovery" in certain environmental aspects (Table 1) suggests that we might be able to handle possible trade-offs between economic slowdown and environment quality in a better manner.

Other lessons learned include recognition that lockdowns or reduced human activities are not sufficient to reduce or prevent extensive and massive fires occurring in abnormally dry years such as those experienced in the western United States (National Interagency Coordination Center 2021). We also learned (counter to expectations) that connectivity to other cities appears to be more important than city size in determining the spread of the virus as evidenced by the experience of Shanghai and Beijing, New York City being an exception (Bai et al. 2020). Corollary effects of reduced international and intercontinental travel to slow the pandemic may include reducing the introduction or spread of invasive species and other diseases. Similarly, the increased hygiene (washing hands frequently) might have also prevented infection from cold, flu or other microorganisms, and mask-wearing and social distancing are equally or more important, for example in preventing flu in the United States this past flu season. Although it's unlikely that international travel will be permanently reduced, people may think twice in the future when handling or contacting wildlife species from which infectious zoonotic diseases emerge (Di Marco et al. 2020). The pandemic lockdowns at varying levels (and also 
on and off multiple times in some places over the year) have made scientists, environmentalists, and the general public think and balance the benefits and adverse effects of fast-accelerated globalization in the past few decades (Smith et al. 2007; Farzanegan et al. 2021).

Ecologists should take advantage of this extremely rare global event to monitor whether and how habitats and environmental conditions improve when human activities are significantly reduced. Since the spatial extents and durations of lockdowns have varied substantially across the globe, spatial trends could be assessed in new studies by comparing regions with different levels of restrictions (from none to total lockdowns). To assess temporal trends, studies could examine environmental changes following the initiation of restrictions or lockdowns, instead of just making a dichotomous comparison between "before and after" (Liu et al. 2020). More importantly, these studies should continue even after all human activities return to normal, or close to it. This is critical as different environmental variables may have different time lags in responses to the same level of lockdown. Ideally, the spatial and temporal dimensions could be combined to examine how the responses from different variables may be intertwined and to discern indirect and interactive effects (ZambranoMonserrate et al. 2020; Cooke et al. 2021). To achieve this, research efforts could be simultaneously and jointly coordinated at multiple levels across the globe; this implies that broadscale collaboration will be essential.

With growing human population and climate change, the risk of additional pandemic events like COVID-19 could be on the rise. To avoid the issues associated with the restricted fieldwork due to extraordinary events such as COVID-19, more automated monitoring and instrumented systems are vital (e.g., newly installed instruments such as data loggers and wireless sensors at the NEON sites across the USA-https://www.neonscience.org/about-neon-fieldsites). More sophisticated (e.g., artificial intelligence or AI) recording (e.g., airborne remote sensing) and manipulating networks could also be deployed in greenhouse and other lab experimental settings. With the rapid development in machine learning and big data availability from citizen science, as well as cellphone/media data (e.g., Facebook, Twitter), we may be able to perform more sophisticated simulations (Mello and Wang 2020) and test whether existing models are useful for modeling COVID19 impacts (Shea et al. 2020).

\section{MAJOR KNOWLEDGE GAPS}

Research on COVID-19 and related matters is rapidly expanding but many uncertainties remain (Table 1, Fig. 1). Some of the related research activities missed the early opportunities after COVID-19 lockdowns started, in part because the scientific community was not fully prepared for an unprecedented event. The initiation of lockdowns offered a very narrow window for actions, and there was no standard protocol and coordination across the globe, especially for early efforts.

\section{Major research tasks include}

(1) Improving the reliability of predictions of the spread of COVID-19 (Edeling et al. 2020). This requires a clear understanding of the virus' ecology and evolutionary biology, e.g., its variants, mutation, and host spectrum from humans to wildlife. In this regard, the virus might be viewed as a human-transmitted "invasive species"; thus, some commonly accepted principles in invasion biology may also apply (Jeschke et al. 2013). Currently, data are lacking regarding the virus' optimal, maximum, or minimum thresholds for temperature or moisture (i.e., the limiting climate factors around its thermal niche). It is also unclear how long the virus can survive and remain infectious on various wet or dry surfaces. It is especially puzzling why many betacoronaviruses such as SARS-CoV-2 that originate in relatively warmer regions (if they indeed originated in bats) can tolerate or prefer "extreme" cold conditions (e.g., the virus was frequently found in frozen meat and sea food packages). Furthermore, the full spectrum of vectors is not known (e.g., even whether it is airborne was still being debated not long ago). Since most infectious diseases originate from the tropics, climate warming is likely to enhance their spread across latitudes. In this regard, more sophisticated simulations and well-designed and strictly controlled experiments could be very helpful.

(2) Understanding the interplay among positive and negative feedback mechanisms on multiple fronts, a.k.a. the "vicious circle" (Cinquin and Demongeot 2002). It is incomplete to recognize that there are both positive and negative effects of the pandemic; the more difficult issues to resolve may be positive outcomes that reinforce behaviors or processes that have delayed or indirect negative consequences. For example, many individuals in the United States have sought refuge from the pandemic in natural parks and public forests-positive behaviors that improve mental health and enhance personal connections with natural systems even as they add additional stress to those systems and exacerbate management challenges.

(3) Understanding whether and to what degree differences in human social community structure and other

(C) This is a U.S. government work and not under copyright protection in the U.S.; foreign copyright protection may apply 2021 
related aspects are linked to the spread of viruses. For example, recent studies by Al-Kindi et al. (2020) and Selcuk et al. (2021) showed that the spread rate of COVID-19 was strongly related to human population density. Also, without an effective lockdown, COVID-19 was more likely to spread among regions and communities with stronger social network connections (Kuchler et al. 2020). Human population heterogeneity was found to some degree to help resist virus infections (Britton et al. 2020). This extremely broad subject covers disparities in many aspects such as social-economic status, ethnic groups, mobility, and connectivity (e.g., urban vs. rural). All such factors should be considered along with lockdowns (i.e., sequence, partial vs. full), herd immunity (Hulme et al. 2020), and vaccine distributions.

(4) Investigating how COVID-19 in humans might have affected other wildlife species through human-wildlife interactions (HWIs). For example, to date at least 12,000 mink have been found dead as coronavirus spreads among fur farms in Utah and Wisconsin (https://www.yahoo.com/news/least-12-000-minkdead-213454137.html).

(5) Developing standard protocols for closely monitoring and evaluating possible related risks, including maintaining frequently updated inventories (part of the surveillance) of wildlife markets (i.e., wet markets) (Watsa 2020) with the purpose of identifying possible emerging infectious diseases (EID). People that are often involved in intense human-wildlife interactions (HWIs) and contact, especially in tropical/subtropical regions, should be well trained and frequently reminded of potential risks.

(6) Better predicting new potential pandemic diseases that may emerge in the near future, especially under climate and land use changes, and how we can avoid pandemic emergence (Altizer et al. 2013; Merow and Urban 2020). Relative to SARS, which mostly occurs in cold weather, coronaviruses appear less sensitive to temperature changes (N- vs. S-hemisphere), although winter seems more favorable to the virus (Poirier et al. 2020). As of a year and a half after the initial report of COVID-19 in December 2019, scientists should have better insight regarding the sensitivity of the virus to seasonal changes. Despite recent advances in modeling techniques in both climate and diseases, mismatch or deviation between the true spread of COVID-19 and modeling results still provides a major and persistent challenge ahead. On the one hand, some novel factors or mechanisms that facilitate the spread of COVID-19 have just been discovered (e.g., Rowe et al. 2021; Selcuk et al. 2021) and other possible hidden factors need to be explored. For example, Rohrer et al.
(2020) reported a close link between peaks of fine particulate matter (PM2.5) and the sudden explosive spread of COVID-19 in Europe. Gupta et al. (2020) discovered that COVID-19 transmission was strongly correlated with certain weather patterns, rather than with any individual weather parameter. Li et al. (2020) showed that aerosol optical depth partly predicted COVID-19-related fatality rates in parts of Europe. In addition to all the factors above, with ongoing climate changes, whether and how "old" diseases may emerge as new threats (e.g., the new SARS-CoV-2 variant or "escape mutant") deserve immediate attention.

(7) Preparing for identified potential and lurking zoonotic viruses that soon may infect humans-that is, act quickly on early detection, early warning, early eradication (3Es; see Fig. 1). Recently, Edwards et al. (2020) identified a swine coronavirus that could potentially spread to humans, and efforts have been made to discover the potential of SARS-CoV vaccine candidates to protect swine. As human-wildlife contacts are increasing, much work in this area remains to be done. Many national and local government agencies have identified wildlife species through which potential diseases may spread into humans (e.g., US Centers for Disease Control and Prevention [CDC] www.cdc.gov/healthypets/ diseases/index.html; US Washington State, www. doh.wa.gov/YouandYourFamily/IllnessandDisease/ AnimalTransmittedDiseases). However, given that pandemics at the COVID-19 level are rare, insufficient attention has been dedicated to understanding these phenomena. In addition, many contemporary studies on the virus and disease focus on near-term results and their long-term consequences are not clear. Now is the time to make these much-deserved coherent and cohesive efforts (e.g., Global Infectious Disease and Epidemiology Network or GIDEON, www.gideononline.com/ (Smith et al. 2007), and "One Health": www.who.int/news-room/q-a-detail/ one-health). The development of universal protocols for practicing caution around animals is not simple, especially when symptoms among both domestic and wild animals may not be known or obvious.

\section{NEW CHALLENGES AND PERSPECTIVES}

Although the pandemic lockdowns have brought some ecological benefits, they also created new challenges. One example is pollution due to the accumulation of plastic waste resulting from the drastically increased usage of masks, gloves and other safety practices (Adyel 2020), 
shipments of goods that utilize disposable packages, and delivery of groceries and foods (i.e., from supermarkets, stores and local restaurants). Clearly, society was not prepared for many of these consequences. Other frequently ignored issues associated with infectious diseases to humans include whether and to what degree such infectious diseases have spilled over (e.g., through vector switching) to domestic and wild animals and then have spilled back to humans. Possible genetic modifications when viruses interact with different hosts could make matters worse (Oude Munnink et al. 2020).

It is possible that many of the observed quick recoveries in environmental conditions may not be sustained once human activities return to pre-COVID-19 level. One of the most important lessons is that some improvement in environmental conditions can be achieved through thoughtful and decisive action (Table 1). Before and during the lockdowns, many people have tried to store and save food, water, and other daily materials. The same precaution and practice could be used for future unforeseen disastrous events to save life and protect the environment. The global COVID-19 lockdown experiment might portend whether some of the benefits from the lockdown could be retained if businesses are re-opened with adjusted and improved operation models. Tourism provides one example. The immediate or short-term effects of COVID-19 on national and international tourism are clear and devastating as it has led to either complete shutdown, travel reductions or strong disruptions (Bakar and Rosbi 2020). Yet, its long-term effects remain elusive, depending on whether there are certain permanent policy shifts and behavioral changes. It is possible that future complete or partial shutdowns will become more frequent when other infectious diseases emerge (as precautions) after all the lessons learned from the COVID-19 crisis (Karabulut et al. 2020). Future global travel could be reduced and become more expensive, with additional and more complicated procedures (e.g., at the airports and at customs checkpoints), more ubiquitous touchless technologies, and more out-of-the-way and independent lodging. Also, more vaccine and testing certificates may be required as an international travel requirement.

To date, we have learned that some pre-lockdown productivity (especially involving internet technologies and digital economies) can indeed be restored and/or sustained without returning to pre-lockdown levels of human activities (e.g., through telework and distance learning) (Buxton et al. 2020). This suggests that some pre-lockdown level of human activities could be permanently lowered. Exploring how to improve economic structure or business operations allows us to be prepared for future possible disastrous events. For example, the previous pattern of using home residences and offices/working locations part time (i.e., people drove to work and left their homes empty), might give way to a new mode of working that utilizes both locations more efficiently. Reduced, more efficient land uses reserved for human activities could increase the space available for wildlife conservation, while decreasing the chances of transmitting new zoonotic diseases (Dobson et al. 2020; Gibb et al. 2020). For example, new houses could include larger office spaces for tele-communication, while much of the traditional office spaces and the large economy built around the millions of people coming to and going from workplaces may be significantly reduced. This has huge implications for future urban ecosystems (e.g., reduced numbers of office buildings, hotels, gyms, and restaurants, among others) and impacts on transportation network planning are not yet fully appreciated.

In summary, while society copes with the reality of COVID-19 and plans to avoid similar pandemics in the future, ecologists have much to contribute by paying close attention to what happens during this unprecedented and unique event. Both short- and long-term environmental consequences and implications of COVID-19 and associated lockdowns need to be continuously and closely examined. Future efforts to improve human health while protecting wildlife and the environment require better understanding and possible constraints on human-wildlife interactions (Lindsey et al. 2020). Swift actions that promote the 3Es (Fig. 1) would be most effective in avoiding similar pandemics. Such unusual times necessitate exceptional measures, funding, and collaboration at a global scale. A recent regional European effort targeting future epidemics (e.g., epidemiological surveillance, early-alert systems) (www.nature.com/articles/d41586-020-02966-2) offers a promising start. The US National Academies of Science, Engineering, and Medicine (NASEM) also recently launched the Response and Resilient Recovery Strategic Science Initiative (www.nationalacademies.org/ our-work/). Many other countries have similar initiatives under way. Ultimately, synchronized coordination in monitoring and prevention measures across local-regionalglobal governments and communities offer the most promise despite existing political and social challenges (Bivins et al. 2020; Liu et al. 2020).

Acknowledgements We greatly appreciate the stimulating discussions with colleagues and constructive comments from G. Nunez-Mir, J. McNeely, L. Pomara, K. Potter, and three anonymous reviewers. Any use of trade, firm, or product names is for descriptive purposes only and does not imply endorsement by the US Government. 


\section{REFERENCES}

Adyel, T.M. 2020. Accumulation of plastic waste during COVID-19. Science 369: 1314-1315.

Al-Kindi, K.M., A. Alkharusi, D. Alshukaili, N. Al Nasiri, T. AlAwadhi, Y. Charabi, and A.M. El Kenawy. 2020. Spatiotemporal assessment of COVID-19 spread over Oman using GIS techniques. Earth Systems and Environment 4: 797-811.

Altizer, S., R.S. Ostfeld, P.T. Johnson, S. Kutz, and C.D. Harvell. 2013. Climate change and infectious diseases: From evidence to a predictive framework. Science 341: 514-519.

Bai, X., H. Nagendra, P. Shi, and H. Liu. 2020. Cities: Build networks and share plans to emerge stronger from COVID-19. Nature 584: 517-520.

Bakar, N.A., and S. Rosbi. 2020. Effect of Coronavirus disease (COVID-19) to tourism industry. International Journal of Advanced Engineering Research and Science 7: 189-193.

Bivins, A., D. North, A. Ahmad, W. Ahmed, E. Alm, F. Been, P. Bhattacharya, L. Bijlsma, et al. 2020. Wastewater-based epidemiology: Global collaborative to maximize contributions in the fight against COVID-19. Environmental Science \& Technology 54: 7754-7757.

Britton, T., F. Ball, and P. Trapman. 2020. A mathematical model reveals the influence of population heterogeneity on herd immunity to SARS-CoV-2. Science 369: 846-849.

Buckley, R. 2020. Conservation implications of COVID19: Effects via tourism and extractive industries. Biological Conservation 247: 108640 .

Buxton, R.T., J.N. Bergman, H.Y. Lin, A.D. Binley, S. Avery-Gomm, R. Schuster, D.G. Roche, and J.R. Bennett. 2020. Three lessons conservation science can learn from the COVID-19 pandemic. Conservation Biology 34: 1331-1332. https://doi.org/10.1111/ cobi.13652.

Cawthorn, D.-M., A. Kennaugh, and S.M. Ferreira. 2021. The future of sustainability in the context of COVID-19. Ambio 50: 812-821. https://doi.org/10.1007/s13280-020-01430-9.

Cinquin, O., and J. Demongeot. 2002. Positive and negative feedback: Striking a balance between necessary antagonists. Journal of Theoretical Biology 216: 229-241.

Cooke, S.J., R.L. Cramp, C.L. Madliger, J.N. Bergman, C. Reeve, J.L. Rummer, K.R. Hultine, A. Fuller, et al. 2021. Conservation physiology and the COVID-19 pandemic. Conservation Physiology 9: coaa139.

Corlett, R.T., R.B. Primack, V. Devictor, B. Maas, V.R. Goswami, A.E. Bates, L.P. Koh, T.J. Regan, et al. 2020. Impacts of the coronavirus pandemic on biodiversity conservation. Biological Conservation 246: 108571.

Derryberry, E.P., J.N. Phillips, G.E. Derryberry, M.J. Blum, and D. Luther. 2020. Singing in a silent spring: Birds respond to a halfcentury soundscape reversion during the COVID-19 shutdown. Science 370: 575-579.

Di Marco, M., M.L. Baker, P. Daszak, P. De Barro, E.A. Eskew, C.M. Godde, T.D. Harwood, M. Herrero, et al. 2020. Opinion: Sustainable development must account for pandemic risk. Proceedings of the National Academy of Sciences of the United States 117: 3888-3892.

Diffenbaugh, N.S., C.B. Field, E.A. Appel, I.L. Azevedo, D.D. Baldocchi, M. Burke, J.A. Burney, P. Ciais, et al. 2020. The COVID-19 lockdowns: A window into the Earth System. Nature Reviews Earth \& Environment 1: 470-481.

Dobson, A.P., S.L. Pimm, L. Hannah, L. Kaufman, J.A. Ahumada, A.W. Ando, A. Bernstein, J. Busch, et al. 2020. Ecology and economics for pandemic prevention. Science 369: 379-381.

Edeling, W., A. Hamid, R. Sinclair, D. Suleimenova, K. Gopalakrishnan, B. Bosak, D. Groen, I. Mahmood, et al. 2020. Model uncertainty and decision making: Predicting the Impact of COVID-19 Using the CovidSim Epidemiological Code. https:// www.researchsquare.com/article/rs-82122/v3. Accessed 29 April 2021

Edwards, C.E., B.L. Yount, R.L. Graham, S.R. Leist, Y.J. Hou, K.H. Dinnon, A.C. Sims, J. Swanstrom, et al. 2020. Swine acute diarrhea syndrome coronavirus replication in primary human cells reveals potential susceptibility to infection. Proceedings of the National Academy of Sciences of the United States 117: 26915-26925.

Farzanegan, M.R., M. Feizi, and H.F. Gholipour. 2021. Globalization and the outbreak of COVID-19: An empirical analysis. Journal of Risk and Financial Management 14: 105.

Gibb, R., D.W. Redding, K.Q. Chin, C.A. Donnelly, T.M. Blackburn, T. Newbold, and K.E. Jones. 2020. Zoonotic host diversity increases in human-dominated ecosystems. Nature 584: 398-402.

Gupta, A., B. Pradhan, and K.N.A. Maulud. 2020. Estimating the impact of daily weather on the temporal pattern of COVID-19 outbreak in India. Earth Systems and Environment 4: 523-534.

Hallema, D.W., F.-N. Robinne, and S.G. McNulty. 2020. Pandemic spotlight on urban water quality. Ecological Processes 9: 1-3.

Huang, X., A. Ding, J. Gao, B. Zheng, D. Zhou, X. Qi, R. Tang, J. Wang, et al. 2021. Enhanced secondary pollution offset reduction of primary emissions during COVID-19 lockdown in China. National Science Review 8: nwaa137.

Hulme, P.E., R. Baker, R. Freckleton, R.S. Hails, M. Hartley, J. Harwood, G. Marion, G.C. Smith, et al. 2020. The Epidemiological Framework for Biological Invasions (EFBI): An interdisciplinary foundation for the assessment of biosecurity threats. NeoBiota 62: 161-192.

Jechow, A., and F. Hölker. 2020. Evidence that reduced air and road traffic decreased artificial night-time skyglow during COVID-19 lockdown in Berlin, Germany. Remote Sensing 12: 3412.

Jeschke, J.M., F. Keesing, and R.S. Ostfeld. 2013. Novel organisms: Comparing invasive species, GMOs, and emerging pathogens. Ambio 42: 541-548. https://doi.org/10.1007/s13280-013-0387-5.

Karabulut, G., M.H. Bilgin, E. Demir, and A.C. Doker. 2020. How pandemics affect tourism: International evidence. Annals of Tourism Research 84: 102991.

Kuchler, T., D. Russel, and J. Stroebel. 2020. The geographic spread of COVID-19 correlates with the structure of social networks as measured by Facebook. National Bureau of Economic Research, Cambridge, MA, USA.

Le Quéré, C., R.B. Jackson, M.W. Jones, A.J. Smith, S. Abernethy, R.M. Andrew, A.J. De-Gol, D.R. Willis, et al. 2020. Temporary reduction in daily global CO 2 emissions during the COVID-19 forced confinement. Nature Climate Change 10: 647-653.

Le, T., Y. Wang, L. Liu, J. Yang, Y.L. Yung, G. Li, and J.H. Seinfeld. 2020. Unexpected air pollution with marked emission reductions during the COVID-19 outbreak in China. Science 369: 702-706.

Li, W., R. Thomas, H. El-Askary, T. Piechota, D. Struppa, and K.A.A. Ghaffar. 2020. Investigating the significance of aerosols in determining the coronavirus fatality rate among three European Countries. Earth Systems and Environment 4: $513-522$

Lindsey, P., J. Allan, P. Brehony, A. Dickman, A. Robson, C. Begg, H. Bhammar, L. Blanken, et al. 2020. Conserving Africa's wildlife and wildlands through the COVID-19 crisis and beyond. Nature Ecology \& Evolution 4: 1300-1310.

Liu, Z., P. Ciais, Z. Deng, S.J. Davis, B. Zheng, Y. Wang, D. Cui, B. Zhu, X. Dou, and P. Ke. 2020. Carbon monitor: A near-real-time daily dataset of global $\mathrm{CO}_{2}$ emission from fossil fuel and cement production. Preprint at arXiv 2006: 07690. 
McNeely, J.A. 2021. Nature and COVID-19: The pandemic, the environment, and the way ahead. Ambio 50: 767-781. https://doi. org/10.1007/s13280-020-01447-0.

Mello, M.M., and C.J. Wang. 2020. Ethics and governance for digital disease surveillance. Science 368: 951-954.

Merow, C., and M.C. Urban. 2020. Seasonality and uncertainty in COVID-19 growth rates. Proceedings of the National Academy of Sciences of the United States 117: 27456-27464.

National Interagency Coordination Center. 2021. Wildland fire summary and statistics annual report: 2020. https://www. predictiveservices.nifc.gov/intelligence/2020_statssumm/intro_ summary20.pdf. Accessed 17 June 2021.

Oude Munnink, B.B., R.S. Sikkema, D.F. Nieuwenhuijse, R.J. Molenaar, E. Munger, R. Molenkamp, A. van der Spek, P. Tolsma, et al. 2020. Transmission of SARS-CoV-2 on mink farms between humans and mink and back to humans. Science 371: 172-177.

Phillips, C.A., A. Caldas, R. Cleetus, K.A. Dahl, J. Declet-Barreto, R. Licker, L.D. Merner, J.P. Ortiz-Partida, et al. 2020. Compound climate risks in the COVID-19 pandemic. Nature Climate Change 10: 586-588.

Poirier, C., W. Luo, M.S. Majumder, D. Liu, K.D. Mandl, T.A. Mooring, and M. Santillana. 2020. The role of environmental factors on transmission rates of the COVID-19 outbreak: An initial assessment in two spatial scales. Scientific Reports 10: 17002.

Rohrer, M., A. Flahault, and M. Stoffel. 2020. Peaks of fine particulate matter may modulate the spreading and virulence of COVID-19. Earth Systems and Environment 4: 789-796.

Rowe, B.R., A. Canosa, J.-M. Drouffe, and J.B. Mitchell. 2021. Simple quantitative assessment of the outdoor versus indoor airborne transmission of viruses and covid-19. Environmental Research 198: 111189.

Rume, T., and S.D.-U. Islam. 2020. Environmental effects of COVID19 pandemic and potential strategies of sustainability. Heliyon 6 : e04965.

Rutz, C., M.-C. Loretto, A.E. Bates, S.C. Davidson, C.M. Duarte, W. Jetz, M. Johnson, A. Kato, et al. 2020. COVID-19 lockdown allows researchers to quantify the effects of human activity on wildlife. Nature Ecology \& Evolution 4: 1156-1159.

Selcuk, M., S. Gormus, and M. Guven. 2021. Impact of weather parameters and population density on the COVID-19 transmission: Evidence from 81 provinces of Turkey. Earth Systems and Environment 5: 87-100.

Shea, K., M.C. Runge, D. Pannell, W.J. Probert, S.-L. Li, M. Tildesley, and M. Ferrari. 2020. Harnessing multiple models for outbreak management. Science 368: 577-579.
Sicard, P., A. De Marco, E. Agathokleous, Z. Feng, X. Xu, E. Paoletti, J.J.D. Rodriguez, and V. Calatayud. 2020. Amplified ozone pollution in cities during the COVID-19 lockdown. Science of the Total Environment 735: 139542.

Smith, K.F., D.F. Sax, S.D. Gaines, V. Guernier, and J.F. Guegan. 2007. Globalization of human infectious disease. Ecology 88: 1903-1910.

Tan, M. K., and T. Robillard. 2021. Population divergence in the acoustic properties of crickets during the COVID-19 pandemic. Ecology 102: e03323.

Tobías, A., C. Carnerero, C. Reche, J. Massagué, M. Via, M.C. Minguillón, A. Alastuey, and X. Querol. 2020. Changes in air quality during the lockdown in Barcelona (Spain) one month into the SARS-CoV-2 epidemic. Science of the Total Environment 726: 138540.

Venter, Z.S., K. Aunan, S. Chowdhury, and J. Lelieveld. 2020. COVID-19 lockdowns cause global air pollution declines. Proceedings of the National Academy of Sciences Od the United States 117: 18984-18990.

Watsa, M. 2020. Rigorous wildlife disease surveillance. Science 369: 145-147.

$\mathrm{Wu}, \mathrm{T} .2021$. The socioeconomic and environmental drivers of the COVID-19 pandemic: A review. Ambio 50: 822-833. https://doi. org/10.1007/s13280-020-01497-4.

Zambrano-Monserrate, M. A., M. A. Ruano, and L. Sanchez-Alcalde. 2020. Indirect effects of COVID-19 on the environment. Science of the Total Environment 728: 138813.

Publisher's Note Springer Nature remains neutral with regard to jurisdictional claims in published maps and institutional affiliations.

\section{AUTHOR BIOGRAPHIES}

Qinfeng Guo $(\triangle)$ is a Research Scientist at the USDA-FS Southern Research Station. He is interested in invasion biology, community ecology, and biogeography.

Address: USDA Forest Service, Southern Research Station, 3041 Cornwallis Road, Research Triangle Park, NC 27709, USA.

e-mail: qinfeng.guo@usda.gov

Danny C. Lee is the director of the USDA-FS Southern Research Station's Center for Forest Assessment and Synthesis. His expertise is in systems ecology, landscape ecology, and application of risk assessment and decision analysis to forest management.

Address: USDA Forest Service, Southern Research Station, 200 WT Weaver Blvd, Asheville, NC 28804, USA. 